\title{
Transitional metaplasia in intestinal epithelium of rats submitted to intestinal cystoplasty and treatment with L-lysine ${ }^{1}$
}

Alessandra Marques dos Santos', Joao Paulo Ferreira Coelho", Camila de Carvalho Juanes", Rafael Barbosa de Azevedo", Clara Araujo Diniz"', Francisco Vagnaldo Fechine Jamacaru'v , Conceição Aparecida Dornelas ${ }^{\vee}$

'Fellow Master degree, Postgraduate Program in Pathology, Department of Pathology, Universidade Federal do Ceará (UFC), Brazil. Intellectual and scientific content of the study, histopathological examinations, technical procedures, manuscript preparation.

"Graduate student, Scientific Iniciation Program, UFC, Fortaleza-CE, Brazil. Technical procedures.

"'Graduate student, Scientific Iniciation Program, UFC, Fortaleza-CE, Brazil. Acquisition of data.

IVPhD, Researcher, Núcleo de Pesquisa e Desenvolvimento de Medicamentos (NPDM), School of Medicine, UFC, Fortaleza-CE, Brazil. Analysis and interpretation of data, statistical analysis.

VPhD, Associate Professor, Department of Pathology, UFC, Fortaleza-CE, Brazil. Conception and design of the study, technical procedures, critical revision, supervised all phases of the study.

\section{Abstract}

Purpose: To evaluated the effects of L-lysine on the intestinal and urothelial epithelia in cystoplasty in rats.

Methods: Twenty-eight 9-week-old rats were assigned to 4 groups: Group A ( $n=8)$ cystoplasty followed by administration of L-lysine $(150 \mathrm{mg} / \mathrm{kg}$ body weight by gavage) for 30 weeks; Group B ( $n=8)$ cystoplasty + water for 30 weeks; Group C $(n=6)$ L-lysine for 30 weeks; Group $D(n=6)$ water for 30 weeks.

Results: On histopathology with hematoxylin and eosin, mild to moderate hyperplasia transitional was observed in at the site of anastomosis in all animals submitted to cystoplasty (Groups A and B), but "transitional metaplasia" of the intestinal glandular epithelium was more accentuated in Group A ( $p=0.045)$. No inflammatory cells, dysplasia or abnormalities were observed. Staining with Alcian blue revealed a substantial reduction of goblet cells and mucins in the colon segment (Groups A and B).

Conclusion: The administration of L-lysine to rats accelerated the development of transitional metaplasia in the epithelium of the colon segment in cystoplasty.

Key words: Urinary Diversion. Carcinogenesis. Lysine. Rats. 


\section{- Introduction}

The first case of carcinogenesis in ureterosigmoidostomy was described in $1929^{1}$, but it wasn't until the first case of neoplasia in a uretero-ileal diversion was reported that it became clear that feces was not the causal factor and systematic investigations of oncogenesis in urinary diversions were initiated ${ }^{2}$.

The introduction of techniques for cystoplasty and urinary diversion to compensate for lost bladder function, using different segments of the gastrointestinal tract, led to the emergence of bladder neoplasias with an extended latency period (Figure 1).

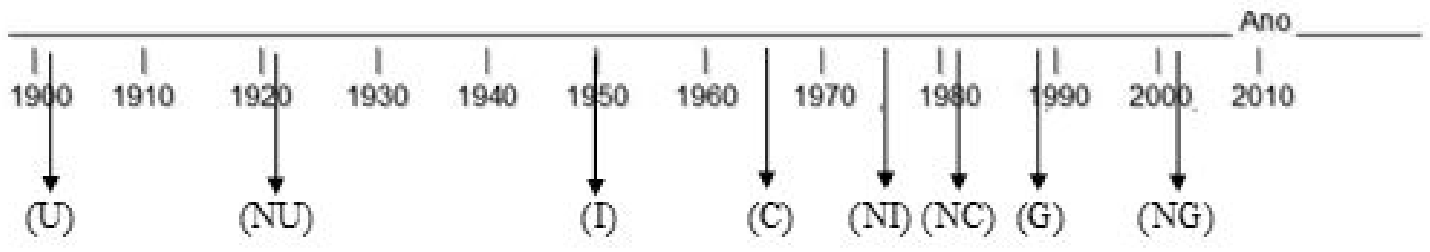

Figure 1 - Timeline of introduction of techniques of plastic repair of urinary tract disorders using different segments of the gastrointestinal tract and the emergence of associated malignant neoplasias.

Source:Adapted from timeline Dornelas ${ }^{7}{ }^{*} 1903$ (U) First Ureterosigmoidostomy; 1921 (NU) First neoplasia of the Ureterosigmoidostomy; 1950 (I) First lleal segment Bricke; 1965 (C) First Colon segment Mogg; 1978 (NI) First neoplasia of the lleal segment; 1982 (NC) First neoplasia of the colon segment; 1988 (G) First Gastrocystoplasty; 2003 (NG) First neoplasia of the Gastrocystoplasty.

Despite current efforts to develop bladder replacement techniques (tissue engineering, stem cell biology, nanotechnology, materials science, regenerative medicine), the currently available technology is insufficient to make bladder reconstruction with biomaterials a standard procedure ${ }^{3}$. Thus, for lack of a better alternative, the use of gastrointestinal segments to reconstruct the bladder (first proposed nearly 150 years ago) remains the gold standard ${ }^{4}$. The long latency period is an argument in favor of the use of gastrointestinal segments, and patients may be followed for early detection of neoplasia and surgery, if necessary.

A recent systematic review of 57 lowevidence studies concluded that the probability of developing cancer after cystoplasty using gastrointestinal segments was $0-5.5 \%$ (annual incidence from 0 to 272.3 per 100,000 cystoplasties). Adenocarcinoma was the most common histological type (51.6\%) and malignant lesions were most often (50\%) associated with vesicointestinal anastomosis ${ }^{5}$.

L-lysine is an essential aminoacid. In a recent study on rats submitted to chemical carcinogenesis of the bladder, L-lysine was found to promote, but not initiate, bladder cancer ${ }^{6}$.

The purpose of this study was evaluate the effect of L-lysine on intestinal and urothelial epithelia in female rats submitted to cystoplasty.

\section{- Methods}

The study protocol followed the ethical principles of the Brazilian College of Animal Experimentation (COBEA) and was approved by the Animal Research Ethics Committee, Universidade Federal do Ceará (UFC). 
The study used 28 female Wistar rats aged 9 weeks and weighing $190 \mathrm{~g}$ on the average, supplied by the UFC experimental animal facility. The animals were kept in polypropylene cages with bedding of autoclaved pine shavings and were given access ad libitum to basic pelleted feed (Luvital ${ }^{\circ}$ ) and water throughout the experiment (except for a short perioperative fast). The laboratory environment was controlled $\left(\sim 25^{\circ} \mathrm{C}\right.$, circadian cycle, continuous air flow).

The animals were distributed into four groups: Group A ( $n=8)$ was submitted to cystoplasty, followed by administration of L-lysine by gavage (g) until the 30th postoperative week (POW); Group B $(n=8)$ was submitted to cystoplasty followed by administration of water (g) for 30 weeks; Group $C(n=6)$ received L-lysine (g) for 30 weeks; Group $D(n=6)$ received water $(g)$ for 30 weeks.

\section{L-lysine}

Aminoacid with the formula $\mathrm{C}_{6} \mathrm{H}_{14} \mathrm{~N}_{2} \mathrm{O}_{2}$ $\mathrm{HCl}$, molecular weight 182.65, CAS number 657-27-2. Diluted in distilled water and administered at $150 \mathrm{mg} / \mathrm{kg}$ body weight/day (1 $\mathrm{mL}$ ) by gavage.

\section{Surgical procedure}

Surgery was performed under a stereoscopic microscope after induction of anesthesia by intraperitoneal administration of ketamine (100 mg/kg body weight) and xylazine $(10 \mathrm{mg} / \mathrm{kg}$ body weight). Suture 70 vicryl thread was used for the vesical-intestinal anastomosis and Suture 30 mononylon thread was used for the abdominal wall.

Using the technique developed by Dornelas ${ }^{7}$, the animals were submitted to cystoplasty with a distal colon segment: The abdominal cavity was opened layer by layer to access the pelvic cavity and resect a $1-\mathrm{cm}$ colon segment, maintaining the vascularization of the branch of inferior mesenteric artery and followed by termino-terminal anastomosis (colon to rectum) closed with a simple suture interrupted every other stitch. The bladder dome was opened and anastomosed with the colon segment, augmenting the bladder, then closed with a single continuous suture (Figure $2 \mathrm{~A}-\mathrm{E})$.

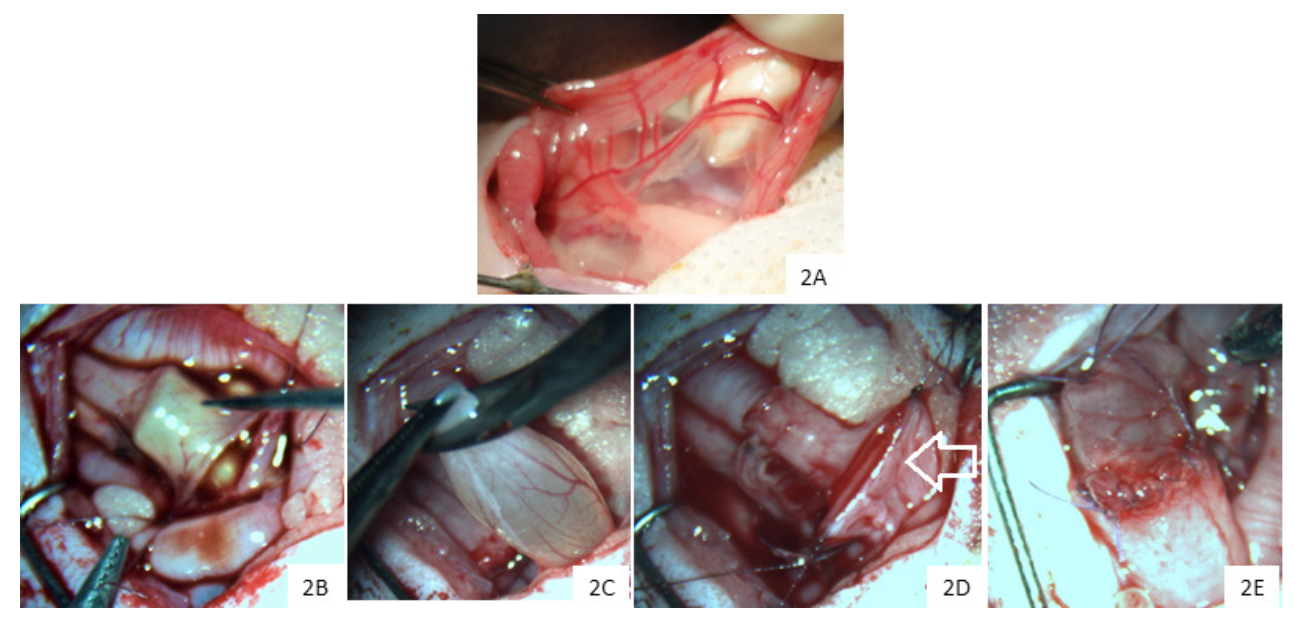

Figure 2 - A. Colon segment. B. Anastomosis of the distal and proximal colon C. Opening of the bladder dome. D. Anastomosis of bladder and colon segment (arrow). E. Colocistoplasty.

Preoperative and postoperative care consisted of a 12-hour fast the night before the procedure and water only (ad libitum) in the first 24 hours after surgery. Gavage with mineral oil $(1 \mathrm{~mL})$ was performed from the 2 nd preoperative day to the 4 th postoperative 
day (POD). Ceftriaxone (i.m.) at $100 \mathrm{mg} / \mathrm{kg}$ body weight and ketoprofen (i.m.) at $5 \mathrm{mg} / \mathrm{kg}$ body weight were administered from 24 hours before surgery to POD 4.

\section{Dissection of abdominal cavity and euthanasia}

In the 30th week after surgery, the animals were anesthetized with ketamine (100 $\mathrm{mg} / \mathrm{kg}$ body weight) and xylazine (10 $\mathrm{mg} / \mathrm{kg}$ body weight) and the abdominal cavity was opened layer by layer with a midline xyphopubic incision. The cavity was methodically inventoried, starting with the bladder, anastomosis, bladder dome (cystoplasty) and kidneys, and proceeding with the remaining abdominal organs. Finally, the animals were euthanized with three additional doses of ketamine and xylazine.

\section{Macroscopy}

After ligating the urethra and both ureters, the augmented bladder was filled with $10 \%$ buffered formaldehyde.

\section{Microscopy}

Lesions were classified following the guidelines for tumors in the rat urinary system published by the International Agency for Research on Cancer ${ }^{8}$ and updated by Oyasu ${ }^{9}$.

\section{Statistical analysis}

\section{All statistical procedures were performed using the software IBM SPSS Statistics (v. 17.0) for Windows ${ }^{\circ}$. Comparisons between the experimental groups regarding the histopathological data were carried out using the Fisher's exact test, with the results expressed as absolute frequencies and percentages. In all analysis, the significance level was set at $5 \%(p<0.05)$.}

\section{- Results}

\section{Mortality following cystoplasty}

In Group A, 3 animals died: one on POD 6 (broncopneumonia peritonitis, dehiscence of colonic anastomosis), one on POD 8 (peritonitis, dehiscence of colonic anastomosis and broncopneumonia) and one in POW 6 (broncopneumonia - Accidental gavage error?). In Group B, 1 animal died of peritonitis and fecaloma on POD 5.

\section{Macroscopy}

On macroscopy, the bladders featured unobstructed colon segments with multiple adhesions to adjacent organs. In some animals, small cysts were seen around the colovesical anastomosis. The bladder wall was thin, without thickening, tumors or stones (Figure 3).

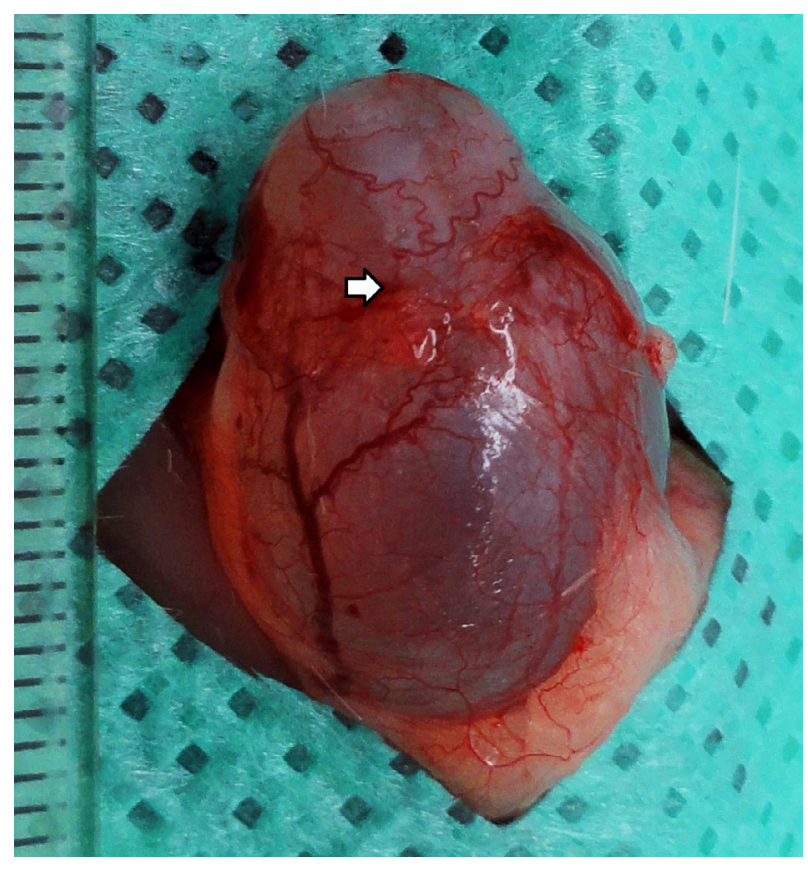

Figure 3 - Rat bladder augmented with colon segment 30 weeks after the procedure (animal from Group A). The arrow indicate the anastomotic site. 


\section{Microscopy}

The microscopic evaluation was informed by standard criteria of animal histopathology $y^{8,9}$. Staining with hematoxylin and eosin (HE) showed a reduction in goblet cells diffusely in the colon segment, and mild to moderate flat and papillary transitional hyperplasia was observed in at the site of anastomosis in all animals submitted to cystoplasty (Groups A and B) and small cysts with simple columnar epithelium were seen in the colovesical anastomosis, In addition, epithelial projection of "transitional metaplasia" some of which with vascular axis, were observed in intestinal crypts and epithelia (Figure 4). But "transitional metaplasia" of the intestinal glandular epithelium was more accentuated in Group A ( $p=0.045)$. No epithelial abnormalities or inflammatory cells were found in the bladders (Table 1).

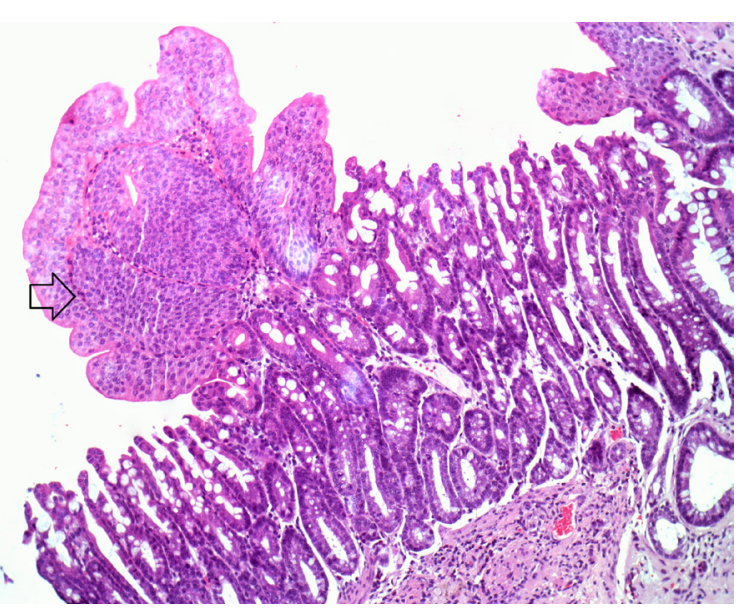

Figure 4 - Transitional metaplasia in intestinal epithelium - arrow (HE, x200).

Table 1 - Histopathological findings for Groups A and B.

\begin{tabular}{llll} 
& Group A & Group B & p-value \\
\hline Inflammation & 0 & 0 & 1.000 \\
Cysts & $0.0 \%$ & $0.0 \%$ & \\
& 2 & 5 & 0.558 \\
Transitional metaplasia in colon segment & $40.0 \%$ & $71.4 \%$ & 0.045 \\
& $3 *$ & 0 & \\
Grade of hyperplasia at the anastomotic site & $60.0 \%$ & $0.0 \%$ & \\
Mild & & & 0.242 \\
Moderate & 1 & 5 & \\
& $20.0 \%$ & $71.4 \%$ & 2 \\
\hline
\end{tabular}

Results expressed as absolute frequencies and percentages. ${ }^{*}=p<0.05$ (Fisher's exact test).

Staining with Alcian blue-PAS showed that goblet cell numbers and mucine production in the crypts of the colovesical epithelia were lower in Groups A and B than in Groups $C$ and $D$ (no surgery) (Figure $5 A$ and $B$ ). 

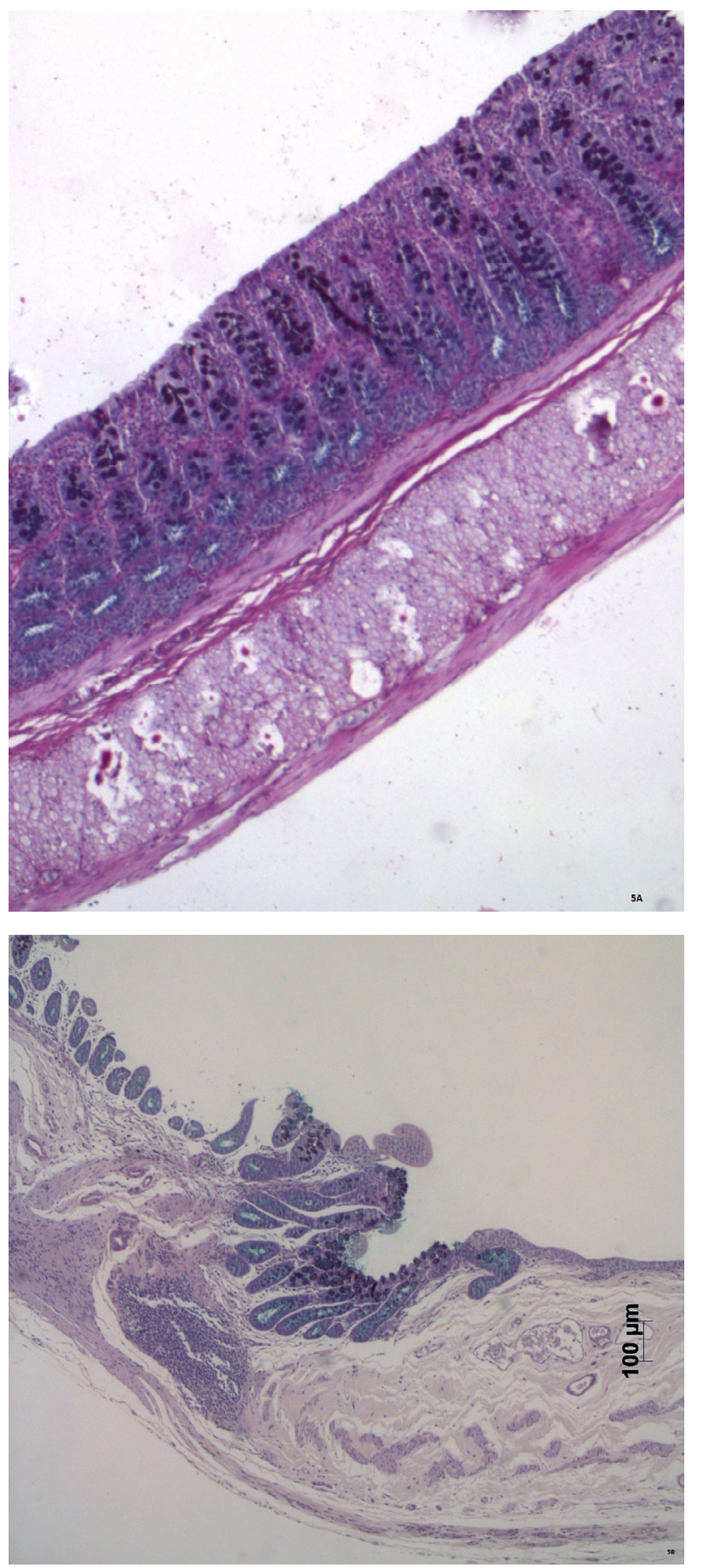

Figure 5 - A. Colonic epithelium of an animal not submitted to cystoplasty (Alcian blue-PAS, $\mathrm{x} 100)$. B. Reduction of goblet cell numbers and mucine production in the crypts of the colovesical epithelium of an animal submitted to cystoplasty.

\section{Discussion}

The pathophysiology of neoplasia in cystoplasties and urinary diversions with gastrointestinal segments has been the object of many hypotheses and theories: nitrosamine formation ${ }^{10}$, traumatism associated with lithiasis, reinfection, surgical thread allergy ${ }^{11-13}$, immature hybrid tissue at the anastomotic site $^{14}$, genomic instability of cells at the anastomotic site ${ }^{15}$, hyperosmolar microenvironment ${ }^{16}$, immunosuppression ${ }^{17}$, cancer-inherent risk of congenital abnormalitie ${ }^{18}$ and many others found in the literature.

In 2009, Husmann ${ }^{18}$ identified 20 cases of bladder cancer following vesicogastrointestinal anastomosis (ileocystoplasty $n=9$; colocystoplasty $n=3$; gastrocystoplasty $n=8$ ). The incidence of cancer per decade of postoperative follow-up was $1.5 \%$ in ileo/colocystoplasty and $2.8 \%$ in vesicogastrocystoplasty ${ }^{18}$.

When investigating histological changes in urinary diversions and their association with mucin gene expression (MUC1 and MUC2) in children and adolescents submitted to gastrocystoplasty, ileocystoplasty and colocystoplasty between 1988 and 2013 ${ }^{19}$, observed an adenocarcinoma in the intestinal segment of the colocystoplasty of an 11-year old child, with upregulated MUC1 expression and downregulated MUC2 expression due to dysplasia. The authors identified these changes as promising early markers of neoplasia in colocystoplasty.

Hyperplasia has been observed in the transitional epithelia of enterovesical and gastrovesical junctions in animals submitted to gastrocystoplasty and ileocystoplasty ${ }^{14}$. On immunohistochemistry, the hyperplastic cells expressed both uroplakins (a molecular marker used in urothelial differentiation) and mucosubstances. The authors hypothesized 
that the hybrid characteristics of these anastomotic cells made them vulnerable to neoplastic changes ${ }^{14}$.

It should be kept in mind that our experiment lasted 30 weeks (7.5 months). This would make the animals' age at the time of euthanasia equivalent to approximately 19 human years.

In this study we looked at carcinogenesis from the perspective of histopathology, analyzing inflammatory aspects and host reactions in the ureter and vesical epithelium and walls in light of Oyasu's theories ${ }^{9}$ on urothelial and vesical carcinogenesis.

The animals submitted to cystoplasty (Groups A and B) displayed mild to moderate urothelial hyperplasia at the anastomotic site similar to that observed by Dornelas ${ }^{7} 18$ months after surgery, without administration of L-lysine. In our study, the administration of $L$-lysine made no significant difference in this respect ( $A$ vs. $B ; p=0.242$ ).

No chronic or acute inflammation was seen in the intestinal and vesical epithelia of animals submitted to cystoplasty (Groups A and $B$ ), but hyperplasia was observed at the anastomotic site, with no significant difference between the groups. The transitional epithelium in the remaining part of the bladder was normal on histology (HE), matching the findings of Dornelas ${ }^{7}$.

The anastomotic site (Groups A and B) presented cysts lined by a single cell layer possibly due to histological artefacts produced surgically by strangulation of the intestinal crypts at the time of surgery. Dornelas ${ }^{7}$ made a similar observation.

Animals submitted to surgery displayed proliferation of cells similar to transitional cells originating from and adhering to the intestinal crypts (transitional metaplasia?), forming projections in the bladder lumen similar to urothelial hyperplasia found near the anastomotic site. However, the number of these projections urothelial was significantly greater in Group A than in Group B ( $p=0.045)$. Referred to as transitional-like ${ }^{20}$ or transitional metaplasia, these histological alterations have been described in experimental studies using animal models of gastrocystoplasty and enterocystoplasty ${ }^{14,21}$ without administration of $L$-lysine. Dornelas ${ }^{7}$ reported the same finding 18 months after surgery, likewise without administration of L-lysine. Could L-lysine have accelerated the development of lesions in Group A?

We know that mesenchyme plays an important role in the development of the epithelia of each organ, Buson et al. ${ }^{21}$ has suggested that a possible conflict of cellular signaling between different mesenchyma and epithelia juxtaposed in gastrocystoplasties could explain the presence of transitional metaplasia and hyperplasia in gastric epithelia. Gitlin et al. ${ }^{14}$ have confirmed that metaplasia with a transitional phenotype with hybrid immunohistochemical (transitional and glandular) characteristics. L-lysine is an essential amino acid that has the function of, among others, stimulating growth through synthesis of growth hormones biosynthesis of proteins and peptides. During tissue repair, in the case of healing of the colovesical junction, the demands of amino acids and proteins are part of this pathological process, we imagine that L-Lysine more easily available orally would accelerate healing by anticipating the appearance of cell proliferation of metaplastic cells. The $\mathrm{L}$ lisine, could it be influencing trophism and cell proliferation and anticipating this phenomenon?

The surface of the gastrointestinal lumen is covered by a mucus layer protecting it against the inhospitable environment. The characteristics and functions of this barrier have been the object of much research as 
changes in barrier composition are known to be associated with severe gastrointestinal problems (inflammatory bowel disorders) ${ }^{22,23}$, urinary diversions with intestinal segments ${ }^{24}$, Barrett's esophagus and colorectal cancer ${ }^{22,23}$. Some changes in MUC gene expression or polymorphism have been detected in inflammatory bowel disorders, but not in malignant transformation ${ }^{23}$.

Histochemically, mucins may be classified into acid and neutral. The former are subdivided into sialomucins and sulphomucins depending on whether they contain sialic acid of sulfates. According to the proportion of $\mathrm{N}$-acetyl or O-acetyl, sialomucins may be further subdivided. Areas rich in neutral mucins stain red with PAS, while areas rich in acids (especially sialomucins) stain blue with Alcianblue $^{25}$. In normal colon mucosa, sialomucin is generally observed in the upper third of the crypts while sulfomucin is observed in the lower two thirds ${ }^{26}$. Patients with adenocarcinoma in the colon and ulcerative rectocolitis display a mucin distribution similar to that found in urinary diversions ${ }^{27}$.

Our histochemical findings for mucins using Alcian blue-PAS show that mucin levels decreased substantially and diffusely in goblet cells in the colon segments used for bladder augmentation (Groups A and B).

Similar reductions in the number of goblet cells and mucins were decribed in studies on cystoplasties and urinary diversions in humans ${ }^{24,28}$ and animal experiments ${ }^{29,30}$. Acid mucin reduction has also been observed in the descending colon of rats submitted to chemical carcinogenesis ${ }^{31}$.

\section{Conclusion}

The administration of L-lysine to rats submitted to colovesical cystoplasty accelerated the development of transitional metaplasia of the intestinal epithelium.

\section{References}

1. Hammer E. Cancer du colon sigmoide dix ans après implantation des uretères d'une vessie exstrophiée. J Urol Nephrol. 1929;28(1): 260-3.

2. Shousha S, Scott J, Polak J. Ileal loop carcinoma after cystectomy for bladder exstrophy. Br Med J. 1978 Aug 5;2(6134):3978. PMID: 687939.

3. Stein JP, Lieskovsky G, Cote R, Groshen $S$, Feng $A C$, Boyd S, Skinner $E$, Bochner $B$, Thangathurai $D$, Mikhail $M$, Raghavan D, Skinner DG. Radical cystectomy in the treatment of invasive bladder cancer: longterm results in 1,054 patients. J Clin Oncol. 2001 Feb 1;19(3):666-75. PMID: 11157016.

4. El-Taji OM, Khattak AQ, Hussain SA. Bladder reconstruction: the past, present and future. Oncol Lett. 2015 Jul;10(1):3-10. PMID: 26170968.

5. Biardeau X, Chartier-Kastler E, Rouprêt $M$, Phé V. Risk of malignancy after augmentation cystoplasty: a systematic review. Neurourol Urodyn. 2016 Aug;35(6):675-82. doi: $10.1002 /$ nau. 22775 .

6. Dornelas CA, Fechine-Jamacaru FV, Albuquerque IL, Magalhães $\mathrm{HI}$, Souza AJ, Alves LA, Almeida PR, Lemos TL, Castro JD, Moraes ME, Moraes MO. Chemoprevention with green propolis extracted in L-lysine versus carcinogenesis promotion with L-lysine in N-butyl-N-[4-hydroxybutyl] nitrosamine (BBN) induced rat bladder cancer. Acta Cir Bras. 2012 Feb;27(2):18592. PMID: 22378376.

7. Dornelas CA. Carcinogênese e derivação urinária: estudo experimental em ratos submetidos à ampliação vesical por segmento de reto (Dissertação). Universidade do Estado do Rio de Janeiro, Faculdade de Ciências Médicas; 1994.

8. International classification of rodent tumours. Part I - The rat. 3. Urinary system. IARC Sci Publ. 1993;(122 Pt I-3):1-46.

9. Oyasu R. Epithelial tumours of the lower urinary tract in humans and rodents. Food Chem Toxicol. 1995 Sep;33(9):747-55. PMID: 7557748.

10. Miwa M, Stuehr DJ, Marletta MA, Wishnok JS, Tannenbaum SR. Nitrosation of amines by stimulated macrophages. Carcinogenesis. 1987;8(7):955-8. PMID: 3560345. 
11.Chester JF, Gaissert HA, Ross JS, Malt RA, Weitzman SA. N-[4-(5-nitro-2-furyl)2-thiazolyl] formamide-induced bladder cancer in mice: augmentation by sutures through the bladder wall. J Urol. 1987 Apr;137(4):769-71. PMID: 3560345.

12.Pozharisski KM. The significance of nonspecific injury for colon carcinogenesis in rats. Cancer Res. 1975 Dec;35(12):382430. PMID: 1104160.

13.Slaga TJ, Klein-Szanto AJ, Triplett LL, Yotti LP, Trosko KE. Skin tumor-promoting activity of Benzoyl Peroxide, a widely use free radicalgenerating compound. Science. 1981 Aug 28;213(4511):1023-5. PMID: 6791284.

14.Gitlin JS, Wu XR, Sun TT, Ritchey ML, Shapiro $E$. New concepts of histological changes in experimental augmentation cystoplasty: insights into the development of neoplastic transformation at the enterovesical and gastrovesical anastomosis. J Urol. 1999 Sep;162(3 Pt 2):1096-100. PMID: 10458439.

15.Appanna TC1, Doak SH, Jenkins SA, Kynaston HG, Stephenson TP, Parry JM. Comparative genomic hybridization (CGH) of augmentation cystoplasties. Int J Urol. 2007 Jun;14(6):539-44. PMID: 17593101.

16.Dixon BP, Chu A, Henry J, Kim R, Bissler JJ. Increased cancer risk of augmentation cystoplasty: possible role for hyperosmolal microenvironment on DNA damage recognition. Mutat Res. 2009 Nov 2;670(1-2):88-95. doi: 10.1016/j. mrfmmm.2009.07.010.

17. Higuchi TT, Granberg CF, Fox JA, Husmann DA. Augmentation cystoplasty and risk of neoplasia: fact, fiction and controversy. J Urol. 2010 Dec;184(6):2492-6. doi: 10.1016/j.juro.2010.08.038.

18.Husmann DA, Spence HM. Current status of tumor of the bowel following ureterosigmoidostomy: a review. J Urol. 1990 Sep;144(3):607-10. PMID: 2201791.

19.Kispal ZF, Kardos D, Jilling T, Kereskai L, Isaacs M, Balogh DL, Pinter AB, Till H, Vajda P. Longterm histological and mucin alterations in the neobladder mucosa following urinary bladder augmentation or substitution with gastrointestinal segment. J Pediatr Urol. 2015 Dec;11(6):349.e1-6. doi: 10.1016/j. jpurol.2015.04.037.

20.Chiarelli SM, Sandei F. Polyps at the site of ureterosigmoidostomy. Tumori. 1984 Apr
30;70(2):209-15. PMID: 6730020.

21.Buson $H$, Diaz DC, Manivel JC, Jessurun J, Dayanc M, Gonzalez R. The development of tumors in experimental gastroenterocystoplasty. J Urol. 1993 Aug;150(2 Pt 2):730-3. PMID: 8326635.

22. Corfield AP, Myerscough N, Longman R, Sylvester P, Arul S, Pignatelli M. Mucins and mucosal protection in the gastrointestinal tract: new prospects for mucins in the pathology of gastrointestinal disease. Gut. 2000 Oct;47(4):589-94. PMID: 10986224.

23.Corfield AP, Carroll D, Myerscough N, Probert CS. Mucins in the gastrointestinal tract in health and disease. Gut. 2000 Oct;47(4):589-94. PMID: 10986224.

24. Moorcraft J, DuBoulay CE, Isaacson $P$, Atwell JD. Changes the mucosa of colon conduits with particular reference to the risk of malignant change. $\mathrm{Br} J$ Urol. 1983 Apr;55(2):185-8. PMID: 6839092.

25.De Faria PC Jr, Andreollo NA, Trevisan MA, Lopes LR. Relationship of the sialomucins (Tn and Stn antigens) with adenocarcinoma in Barrett's esophagus. Rev Assoc Med Bras. 2007 Jul-Aug;53(4):360-4. PMID: 17823742.

26. Filipe MI. Mucous secretion in rat colonic mucosa during carcinogenesis induced by dimethylhydrazine. A morphological and histochemical study. Br J Cancer. 1975 Jul;32(1):60-77. PMID: 1174451.

27.Shamsuddin AK, Trump BF. Colon epithelium. I. Colon epithelium. I. Light microscopic, histochemical, and ultrastructural features of normal colon epithelium of male Fischer 344 rats. J Natl Cancer Inst. 1981 Feb;66(2):375-88. PMID: 6935485.

28.Iannoni C, Marcheggiano A, Pallone F, Frieri G, Gallucci M, Di Silverio F, Caprilli R. Abnormal patterns of colorectal mucin secretion after urinary diversion of different types: histochemical and lectin binding studies. Hum Pathol. 1986 Aug;17(8):83440. PMID: 3089901.

29.Santos AM, Coelho JP, Juanes CC, Azevedo RB, Melo NO, Jamacaru FV, Dornelas CA. Carcinogenesis in rats subjected to a new model ureterosigmoidostomy and treated with L-lysine. Acta Cir Bras. 2016 Dec;31(12):793-800. doi: 10.1590/S0102865020160120000003.

30.Dornelas CA, Santos AM, Correia AL, Juanes Cde C, Coelho JP, Cunha BL, Maciel AV, 
Jamacaru FV. Bladder carcinogenesis in rats subjected to ureterosigmoidostomy and treated with L-lysine. Rev Col Bras Cir. 2016 Mar-Apr;43(2):80-6. doi: 10.1590/010069912016002003.
31.Rubio CA, Rivera F. Quantification of acid mucins in the descending colon of rats having simultaneously growing colonic tumors. APMIS. 1991 Nov;99(11):993-6. PMID: 1958356.

\section{Correspondence:}

Profa. Dra. Conceição Aparecida Dornelas Faculdade de Medicina, Departamento de Patologia e Medicina Legal, UFC Rua Monsenhor Furtado, s/n 60441-750 Fortaleza - CE Brasil Tel.: (55 85)3366-8300 / 3366-8301 eusoucondor@yahoo.com.br

Received: Dec 18, 2016

Review: Feb 17, 2017

Accepted: March 21, 2017
Conflict of interest: none

Financial source: none

${ }^{1}$ Research performed at Laboratory of Experimental, Department of Pathology and UNIFAC, Faculty of Medicine, Universidade Federal do Ceará (UFC), Brazil. Part of Master degree thesis, Postgraduate Program in Pathology. Tutor: Profa. Dra. Conceição Aparecida Dornelas. 